\title{
EXTRAÇÃO E EXPORTAÇÃO DE NUTRIENTES PELO FEIJOEIRO ADUBADO COM NITROGÊNIO, EM DIFERENTES TEMPOS DE IMPLANTAÇÃO DO SISTEMA PLANTIO DIRETO ${ }^{(1)}$
}

\author{
Adelson Antonio Guidolin Perez ${ }^{(2)}$, Rogério Peres Soratto ${ }^{(3)}$, Natalia Politti Manzatto $^{(4)}$ \& \\ Emerson de Freitas Cordova de Souza ${ }^{(5)}$
}

\begin{abstract}
RESUMO
O cultivo do feijoeiro em sistema plantio direto (SPD) tem aumentado de forma marcante no país. Neste contexto, para adubações mais racionais, é fundamental conhecer as exigências nutricionais da cultura quando cultivada em SPD recémimplantado ou consolidado, já que o tempo de implantação do sistema pode alterar a disponibilidade de nutrientes e a resposta das culturas à adubação nitrogenada. Objetivou-se avaliar a extração e exportação de nutrientes pelo feijoeiro em razão da adubação nitrogenada, em solo sob SPD recém-implantado ou consolidado. $O$ experimento foi conduzido por dois anos agrícolas, em um Nitossolo Vermelho distrófico, no município de Botucatu, SP. O delineamento experimental foi em blocos ao acaso, em esquema de parcelas subdivididas, com quatro repetições. As parcelas foram formadas por áreas sob SPD com diferentes tempos de adoção, e as subparcelas constituídas por quatro formas de aplicação do nitrogênio (N) na cultura do feijão (T0: controle, sem aplicação de $N$; T1: $60 \mathrm{~kg} \mathrm{ha}^{-1}$ na pré-semeadura; T2: $60 \mathrm{~kg} \mathrm{ha}^{-1}$ aplicado em cobertura no estádio $V_{4} ;$ e $T 3: 60 \mathrm{~kg} \mathrm{ha}^{-1}$ na pré-semeadura + $60 \mathrm{~kg} \mathrm{ha}^{-1}$ em cobertura). Foram avaliados: matéria seca da parte aérea, concentração e acúmulo de nutrientes na parte aérea, produtividade de grãos e concentrações e exportação de nutrientes nos grãos. O tempo que a área permaneceu sob SPD não influenciou a produtividade, a nutrição e nem mesmo a resposta da cultura do feijão à adubação nitrogenada. A aplicação de $\mathbf{N}$, especialmente em pré-semeadura, proporcionou maiores acúmulos de matéria seca e nutrientes pela cultura do feijão. As concentrações de nutrientes nos grãos
\end{abstract}

(1) Parte da Dissertação de Mestrado apresentada pelo primeiro autor à Faculdade de Ciências Agronômicas, Universidade Estadual Paulista - FCA/UNESP. Recebido para publicação em 28 de agosto de 2012 e aprovado em 25 de junho de 2013.

(2) Engenheiro Agrônomo, M.Sc., Tracan - Máquinas e Sistemas para a Agricultura Ltda. Rua Edson Souto, 620, CEP 14095-250 Ribeirão Preto (SP). E-mail: adelsonperez@uol.com.br

(3) Professor Adjunto do Departamento de Produção e Melhoramento Vegetal, FCA/UNESP, Campus de Botucatu. Caixa Postal 237. CEP 18603-970 Botucatu (SP). Bolsista do CNPq. E-mail: soratto@fca.unesp.br

(4) Engenheira Agrônoma, Monsanto do Brasil Ltda. Av. das Nações Unidas, 12901, Torre Norte, $7^{\circ}$ andar, Brooklin, CEP 04578910 São Paulo (SP). E-mail: natalia.p.manzatto@monsanto.com

(5) Doutorando em Agronomia (Agricultura), FCA/UNESP. E-mail: emerson.cordova@hotmail.com 


\begin{abstract}
foram pouco influenciadas pela adubação nitrogenada. As maiores produtividades de grãos e exportações de nutrientes foram proporcionadas pela aplicação de $\mathbf{N}$ em duas épocas (pré-semeadura e em cobertura) ou apenas em cobertura.
\end{abstract}

Termos de indexação: Phaseolus vulgaris, adubação nitrogenada, manejo do solo, antecipação da adubação, acúmulo de nutrientes.

\title{
SUMMARY: NUTRIENT EXTRACTION AND EXPORTATION BY NITROGEN- FERTILIZED COMMON BEAN GROWN AFTER DIFFERENT PERIODS OF NO-TILLAGE SYSTEM ESTABLISHMENT
}

\begin{abstract}
Common bean grown in no-tillage (NT) systems has increased markedly in Brazil. Thus, to optimize the fertilizer recommendations, it is important to know the nutritional requirements of this crop when grown under new and established NT systems, which can change the nutrient availability and crop response to nitrogen $(N)$ fertilization. The objective was to evaluate the extraction and exportation of nutrients by common bean as function of $N$ fertilization on soil under new and established NT systems. The experiment was carried out in two agricultural years, on a Red Nitosol (Alfisol) in Botucatu, São Paulo State, Brazil. A randomized complete block design was used in a split-plot scheme with four replications. The plots consisted of areas under NT systems after different periods of adoption and the subplots of four forms of $N$ application to common bean (T0: control, without nitrogen; T1: $60 \mathrm{~kg} \mathrm{ha}^{-1}$ before sowing; T2: $60 \mathrm{~kg} \mathrm{ha}^{-1}$ sidedressed at $V_{4}$ stage; and T3: $60 \mathrm{~kg} \mathrm{ha}^{-1}$ before sowing $+60 \mathrm{~kg} \mathrm{ha}^{-1}$ sidedressed). The following properties were evaluated: shoot dry matter, nutrient concentration and accumulation in the shoot, grain yield, and nutrient concentration and exportation in the grains. The NT age did not affect common bean yield, nutrition and response to $N$ management. Nitrogen application, especially before sowing, led to higher dry matter and nutrient accumulation by common bean. The nutrient concentration in grains was little influenced by $N$ fertilization. Grain yield and nutrient exportation were highest after double N application (before sowing and sidedressed) or only sidedressed at $V_{4}$.

Index terms: Phaseolus vulgaris, nitrogen fertilization, soil management, anticipation of fertilization, nutrient accumulation.
\end{abstract}

\section{INTRODUÇÃO}

Nas regiões tropical e subtropical, o sistema plantio direto (SPD) destaca-se por ser uma forma eficiente para manter ou melhorar as condições químicas, físicas e biológicas do solo (Lovato et al., 2004; Figueiredo et al., 2007). Nesse sistema, a cobertura vegetal que permanece sobre o solo controla a erosão, uma vez que evita a desagregação das partículas e o selamento superficial, aumenta a infiltração de água e diminui o escorrimento superficial (Wutke et al., 1993; Hernani et al., 1999).

No SPD, o acúmulo de palhada sobre o solo favorece a reciclagem de nutrientes, a agregação do solo, o armazenamento da água e a manutenção da matéria orgânica do solo (MOS), com efeitos positivos sobre a fertilidade (Boer et al., 2007; Crusciol \& Soratto, 2010). Entretanto, a taxa de mineralização da matéria orgânica é menor, quando comparada com sistema convencional de preparo do solo (Amado \& Mielniczuk, 2000), o que proporciona menor disponibilidade de nitrogênio $(\mathrm{N})$ às plantas, principalmente na fase de implantação até a consolidação do sistema (Sá, 1999; Soratto et al., 2001; Bordin et al., 2003; Figueiredo et al., 2007; Alves Junior et al., 2009). Alguns anos após a adoção do SPD, ocorre estabilização das condições e o caráter fonte e dreno de $\mathrm{N}$ se equivalem; com o passar dos anos, o aporte de $\mathrm{N}$, via decomposição de resíduos, é maior que a quantidade de $\mathrm{N}$ imobilizada pelos microrganismos do solo, o que torna a demanda por N menor (Sá, 1999; Lovato et al., 2004).

Nos últimos anos, tem aumentado o cultivo do feijão (Phaseolus vulgaris L.) em SPD, sem que se saiba as suas exigências nutricionais quando cultivado em solo sob SPD recém-implantado ou consolidado, por diferentes períodos de tempo, já que isso pode alterar a disponibilidade de nutrientes e a resposta das culturas à adubação nitrogenada.

$\mathrm{O} \mathrm{N}$ é o nutriente absorvido em maiores quantidades pelo feijoeiro e, aproximadamente, $50 \%$ do $\mathrm{N}$ absorvido é exportado para os grãos, sendo frequente sua deficiência (Oliveira et al., 1996). Embora parte do $\mathrm{N}$ seja suprida ao feijoeiro por meio da associação com bactérias do gênero Rhizobium, a quantidade fornecida por esse processo é insuficiente (Brito et al., 2011; Souza et al., 2011). O restante do N é obtido da mineralização da MOS e dos fertilizantes nitrogenados (Brito et al., 2011). Assim, para obtenção de alta produtividade é fundamental o fornecimento de $\mathrm{N}$ à cultura do feijão, já que essa é altamente exigente em $\mathrm{N}$ para a produção de grãos. 
O N é um constituinte da molécula de clorofila e, portanto, fundamental para a fotossíntese (Costa et al., 1988), sendo esse o responsável por promover o crescimento vegetativo do feijoeiro (Soratto et al., 2001; 2006; 2008; Soratto et al., 2011; Souza et al., 2011; Maia et al., 2012). O início da floração indica o término da fase vegetativa da planta; assim, até o florescimento, a maior parte de todos os nutrientes deve ter sido assimilada, pois, na fase reprodutiva, a taxa de absorção mineral diminui por causa da redução do crescimento radicular, sendo favorecida a redistribuição de nutrientes da parte vegetativa (caule, folhas e ramas) para a reprodutiva, as vagens (Kluthcouski et al., 2005). Portanto, a maior disponibilidade de $\mathrm{N}$ na fase inicial eleva a produção de matéria seca pelo feijoeiro em SPD (Soratto et al., 2001; 2006; Teixeira et al., 2005; Kluthcouski et al., 2005).

Uma opção para aumentar a disponibilidade de $\mathrm{N}$ no início do crescimento da cultura do feijão, de forma a minimizar o efeito da imobilização pelos microrganismos, seria a aplicação antecipada do $\mathrm{N}$ na pré-semeadura ou na semeadura da cultura (Sá, 1996; Mai et al., 2003; Soratto et al., 2008). Entretanto, altas doses de $\mathrm{N}$ no sulco de semeadura podem comprometer o estabelecimento das plantas de feijão (Teixeira et al., 2005; Santos \& Fageria, 2007; Alves Junior et al, 2009). Em determinadas condições, a aplicação antecipada de $\mathrm{N}$ na pré-semeadura tem propiciado altas produtividades, como a observada por Kluthcouski et al. (2005), em que a aplicação antecipada do $\mathrm{N}$ (incorporação um dia antes da semeadura) resultou em aumento significativo da produtividade de feijão, até a dose de $90 \mathrm{~kg} \mathrm{ha}^{-1} \mathrm{de} \mathrm{N}$, sendo essa mais expressiva até $45 \mathrm{~kg} \mathrm{ha}^{-1}$, o que demonstra que o feijoeiro necessita de $\mathrm{N}$ no período inicial de desenvolvimento. Também, a aplicação de $\mathrm{N}$ em pré-semeadura tem como vantagem o maior rendimento operacional de máquinas, em razão da maior facilidade de distribuição a lanço, da economia de tempo e de mão de obra, do menor custo operacional e da redução no gasto de combustível, lubrificante e reparos (Ceretta, 1998; Lange et al., 2008).

Na literatura, quase não há informações sobre a extração e exportação de nutrientes pela cultura do feijão, quando cultivada sob diferentes formas de manejo do $\mathrm{N}$ e em solo com diferentes tempos de implantação do SPD. $\mathrm{O}$ conhecimento das exigências nutricionais da cultura, nas diversas situações de cultivo, pode contribuir para o aprimoramento das recomendações de adubação nitrogenada. Portanto, esta pesquisa teve como objetivo avaliar a extração e exportação de nutrientes pela cultura do feijão em razão da adubação nitrogenada, em solo sob SPD recém-implantado ou consolidado.

\section{MATERIAL E MÉTODOS}

O experimento foi conduzido na safra "da seca" (semeadura em janeiro) dos anos agrícolas 2007/08 e
2008/09, em Botucatu, SP ( $22^{\circ} 51^{\prime} \mathrm{S}, 48^{\circ} 26^{\prime} \mathrm{W}$ e altitude de $740 \mathrm{~m}$ ). O solo da área experimental é um Nitossolo Vermelho distrófico, textura argilosa (Embrapa, 2006). Segundo a classificação climática de Köppen, o clima predominante na região é do tipo Cwa, caracterizado como tropical de altitude, com inverno seco e verão quente e chuvoso. Os dados climáticos registrados durante o desenvolvimento do experimento estão apresentados na figura 1 .

A área experimental onde foi conduzido o experimento faz parte de um programa de estudos de longo prazo dos sistemas de preparo convencional do solo e SPD (Quadro 1). No ano agrícola 2006/07, toda a área do experimento foi cultivada com soja sem preparo do solo e sem aplicação de $\mathrm{N}$ mineral; no outono-inverno dos anos agrícolas 2007/08 e 2008/09, cultivou-se a aveia amarela (Avena byzantina C. Koch) em sucessão, com preparo convencional do solo e SPD nas respectivas parcelas, sem aplicação de $\mathrm{N}$ em todas as parcelas.

O cultivo do feijão em SPD foi realizado sobre a palhada da aveia amarela, ou seja, sem preparo do solo, em todas as parcelas. As parcelas sob SPD encontravam-se nesse sistema há 23 anos, o que caracteriza como SPD consolidado (SPDC), segundo Sá (1999). Já as demais parcelas foram manejadas na maioria das safras com o sistema convencional de preparo do solo, até a implantação da aveia amarela que antecedeu a cultura do feijão, o que a caracteriza, no caso da cultura do feijão, como um SPD recémimplantado (SPDR), ou em fase de implantação.

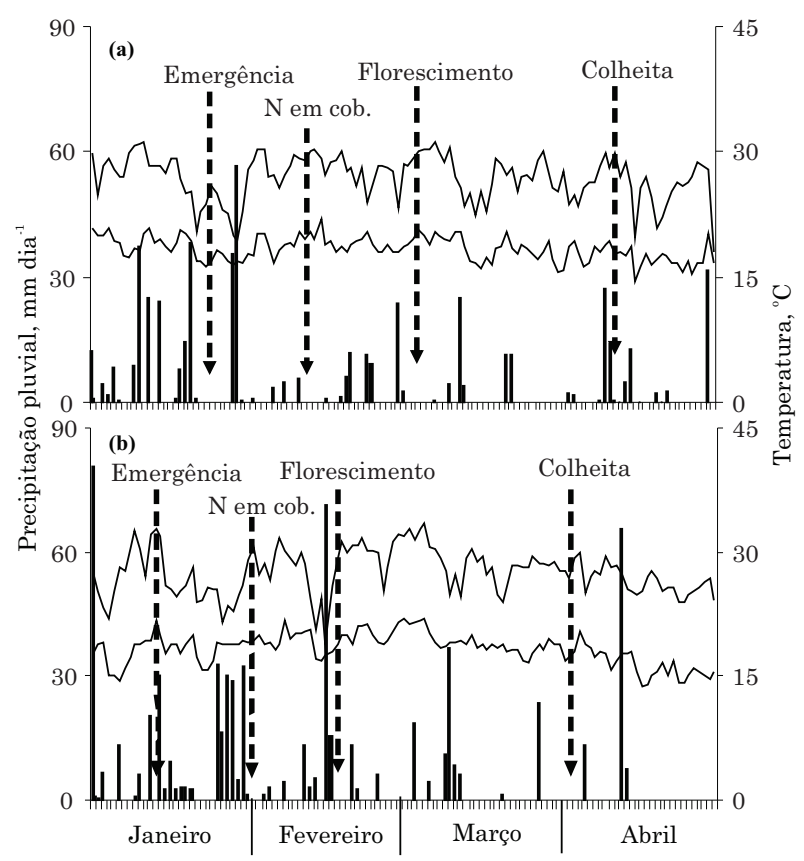

Figura 1. Precipitação pluvial (|), temperaturas máximas (_) e mínimas ( $(-)$ registradas na área do experimento, durante o período de janeiro a abril, nos anos agrícolas 2007/2008 (a) e 2008/2009 (b). Botucatu, SP. 
O delineamento experimental utilizado foi de blocos ao acaso, em esquema de parcelas subdivididas, com quatro repetições. As parcelas foram representadas pelo SPDR - sistema plantio direto recém-implantado (a cultura do feijão foi a primeira a ser implantada no sistema de plantio direto) e SPDC - sistema plantio direto consolidado (23 anos após a implantação); as subparcelas foram constituídas por quatro formas de aplicação do $\mathrm{N}$ na cultura do feijão (T0: controle, sem aplicação de $\mathrm{N} ; \mathrm{T} 1: 60 \mathrm{~kg}^{-1} \mathrm{ha}^{-1} \mathrm{~N}$ antecipado na présemeadura; $\mathrm{T} 2: 60 \mathrm{~kg} \mathrm{ha}^{-1}$ de $\mathrm{N}$ aplicado em cobertura no estádio $\mathrm{V}_{4}$; e T3: $60 \mathrm{~kg} \mathrm{ha}^{-1}$ na pré-semeadura + $60 \mathrm{~kg} \mathrm{ha}^{-1}$ de $\mathrm{N}$ em cobertura no estádio $\mathrm{V}_{4}$ ).

Para o cultivo do feijoeiro, nos anos agrícolas de 2007/08 e 2008/09, fez-se a dessecação das plantas presentes na área, respectivamente, aos 15 e 19 dias antes da semeadura, utilizando o herbicida Glifosato (1440 $\mathrm{g} \mathrm{ha}^{-1}$ do i.a.). Uma semana após a dessecação, foram coletadas amostras de solo em seis pontos por parcela experimental, nas profundidades de 0-10 e 10$20 \mathrm{~cm}$, nos dois anos agrícolas. Essas profundidades foram escolhidas em razão de 83,6 a 97,4 \% do sistema radicular do feijoeiro, na época do florescimento, encontrar-se na camada de $0-20 \mathrm{~cm}$ de profundidade (Inforzato \& Miyasaka, 1963). As amostras compostas foram secadas ao ar, peneiradas (malha $2 \mathrm{~mm}$ ) e submetidas à análise, para determinação das características químicas, segundo métodos descritos por Raij et al. (2001). Também foi determinada a concentração de $\mathrm{N}$ mineral, mediante destilação por arraste de vapor (Raij et al., 2001). Os procedimentos basearam-se na extração do $\mathrm{N}$ inorgânico $\left(\mathrm{NH}_{4}{ }^{+}, \mathrm{NO}_{3}{ }^{-}\right.$ e $\mathrm{NO}_{2}^{-}$) por solução de $\mathrm{KCl} 1 \mathrm{~mol} \mathrm{~L}^{-1}$. Nesse extrato, com a adição de $\mathrm{MgO}$, foi promovida a conversão de $\mathrm{NH}_{4}{ }^{+}$a $\mathrm{NH}_{3}$, que foi separada por destilação. Em seguida, no mesmo extrato, foi acrescentado um produto redutor (Liga de Devarda), que converteu o $\mathrm{NO}_{3}{ }^{-} \mathrm{e} \mathrm{NO}_{2}{ }^{-}$ a $\mathrm{NH}_{3}$, que também foi destilado e recolhido em solução de $\mathrm{H}_{3} \mathrm{BO}_{3}$ + indicador. A determinação de $\mathrm{NO}_{3}$ - foi por titulação com ácido sulfúrico $\left(0,0025 \mathrm{~mol} \mathrm{~L}^{-1}\right)$. Os resultados estão apresentados no quadro 2.

A semeadura do feijão, cultivar Pérola, foi realizada em 17/01/2008 e 06/01/2009, com uma semeadoraadubadora tratorizada, na densidade de 15 sementes por metro de sulco e espaçamento entre fileiras de $0,45 \mathrm{~m}$. No primeiro ano, a adubação de semeadura foi feita com $52 \mathrm{~kg} \mathrm{ha}^{-1} \mathrm{de}_{2} \mathrm{O}_{5}$ (superfosfato triplo) e $38 \mathrm{~kg} \mathrm{ha}^{-1} \mathrm{de}_{2} \mathrm{O}$ (cloreto de potássio), em todas as parcelas. No segundo, foram aplicados $50 \mathrm{~kg} \mathrm{ha}^{-1} \mathrm{de}$ $\mathrm{P}_{2} \mathrm{O}_{5}$ (superfosfato simples) e $30 \mathrm{~kg} \mathrm{ha}^{-1} \mathrm{de}_{2} \mathrm{O}$ (cloreto de potássio). A aplicação do $\mathrm{N}$, na forma de nitrato de amônio $\left(\mathrm{NH}_{4} \mathrm{NO}_{3}\right)$, em pré-semeadura foi feita no mesmo dia, porém antes da semeadura do feijão, com auxílio de uma semeadora-adubadora tratorizada. As plantas emergiram em 24/01/2008 e 13/01/2009, respectivamente, e a adubação de cobertura com $\mathrm{NH}_{4} \mathrm{NO}_{3}$ foi efetuada em 12/02/2008 e 01/02/2009, quando as plantas de feijão encontravam-se no estádio fenológico $\mathrm{V}_{4}$, caracterizado pela 3 a folha trifoliolada expandida (Fernández et al., 1986), sendo o fertilizante distribuído sobre a superfície do solo, em filetes contínuos a $5 \mathrm{~cm}$ das fileiras de plantas. Em todos os tratamentos, o feijoeiro foi conduzido em condições de sequeiro.

O controle de plantas daninhas foi realizado mediante duas aplicações sequenciais do herbicida Fluazifope-p-butílico + Fomezafem $\left(120+150 \mathrm{~g} \mathrm{ha}^{-1}\right.$ do i.a.), nos dias 31/01 e 12/02/2008, no primeiro ano, e nos dias 21/01 e 04/02/2009, no segundo ano. Para o controle de pragas e doenças, foram realizadas pulverizações com inseticidas e fungicidas recomendados para a cultura.

Quando as plantas encontravam-se no estádio $\mathrm{V}_{4}$, imediatamente antes da aplicação de $\mathrm{N}$ em cobertura, foram coletadas 10 plantas por unidade experimental. O material (parte aérea das plantas) foi lavado com

Quadro 1. Descrição dos sistemas de manejo do solo e da rotação de culturas utilizados na área experimental

\begin{tabular}{|c|c|c|c|c|c|}
\hline \multicolumn{5}{|c|}{ Manejo do solo } & \multirow{3}{*}{$\begin{array}{c}\text { Sucessão de culturas } \\
\text { (outono-inverno/ } \\
\text { primavera-verão) }\end{array}$} \\
\hline \multirow{2}{*}{ Ano agrícola } & \multicolumn{2}{|c|}{ SPDR } & \multicolumn{2}{|c|}{ SPDC } & \\
\hline & Outono & Primavera & Outono & Primavera & \\
\hline $1985 / 86$ & Aração+gradagem & Aração+gradagem & Aração+gradagem & Sem preparo & Trigo/soja \\
\hline $1986 / 87$ a $1994 / 95$ & Aração+gradagem & Aração+gradagem & Sem preparo & Sem preparo & Trigo/soja \\
\hline $1995 / 96$ a $1998 / 99$ & Sem preparo & Sem preparo & Sem preparo & Sem preparo & Pousio/pousio \\
\hline $1999 / 00$ & Aração+gradagem & Aração+gradagem & Sem preparo & Sem preparo & Aveia preta/milho \\
\hline $2000 / 01$ e $2001 / 02$ & Sem preparo & Sem preparo & Sem preparo & Sem preparo & Pousio/pousio \\
\hline $2002 / 03$ e $2003 / 04$ & Aração+gradagem & Aração+gradagem & Sem preparo & Sem preparo & Aveia preta/milheto-feijão \\
\hline $2005 / 06$ e $2005 / 06$ & Aração+gradagem & Aração+gradagem & Sem preparo & Sem preparo & Aveia preta/milho \\
\hline $2006 / 07$ & Sem preparo & Sem preparo & Sem preparo & Sem preparo & Pousio/soja \\
\hline $2007 / 08$ & Aração+gradagem & Sem preparo & Sem preparo & Sem preparo & Aveia amarela/feijão \\
\hline $2008 / 09$ & Aração+gradagem & Sem preparo & Sem preparo & Sem preparo & Aveia amarela/feijão \\
\hline
\end{tabular}

SPDR: sistema plantio direto recém-implantado; e SPDC: sistema plantio direto consolidado. 
Quadro 2. Propriedades químicas do solo, nas profundidades de 0-10 e 10-20 cm, em razão do tempo de manejo do solo sob sistema plantio direto, nos anos agrícolas avaliados

\begin{tabular}{|c|c|c|c|c|c|c|c|c|c|c|c|}
\hline Prof. & Manejo do solo & $\mathrm{pH}\left(\mathrm{CaCl}_{2}\right)$ & MO & Presina & $\mathbf{H}+\mathbf{A l}$ & $\mathbf{K}$ & $\mathbf{C a}$ & Mg & CTC & $\mathbf{v}$ & $\mathbf{N}$ mineral \\
\hline \multirow[t]{2}{*}{$\mathrm{cm}$} & & & $\mathrm{g} \mathrm{dm}^{-3}$ & $\mathrm{mg} \mathrm{dm} \mathrm{m}^{-3}$ & \multicolumn{5}{|c|}{$-\mathrm{mmol}_{\mathrm{c}} \mathrm{dm}^{-3}$} & $\%$ & $\mathrm{mg} \mathrm{dm} \mathrm{m}^{-3}$ \\
\hline & & \multicolumn{10}{|c|}{$2007 / 08$} \\
\hline \multirow[t]{2}{*}{$0-10$} & SPDR & 5,2 & 36 & 51,1 & 38,9 & 5,0 & 51,5 & 17,0 & 112,4 & 65 & 12,0 \\
\hline & SPDC & 5,3 & 40 & 81,5 & 38,3 & 5,7 & 61,6 & 22,6 & 128,2 & 70 & 12,6 \\
\hline \multirow[t]{3}{*}{$10-20$} & SPDR & 5,2 & 33 & 36,9 & 39,6 & 3,2 & 61,9 & 19,4 & 124,1 & 68 & 11,9 \\
\hline & SPDC & 5,3 & 31 & 48,4 & 36,4 & 3,1 & 61,7 & 18,7 & 119,9 & 69 & 11,0 \\
\hline & & \multicolumn{10}{|c|}{$2008 / 09$} \\
\hline \multirow[t]{2}{*}{$0-10$} & SPDR & 5,4 & 29 & 46,3 & 37,4 & 4,2 & 34,1 & 14,0 & 89,7 & 58 & 30,2 \\
\hline & SPDC & 5,5 & 30 & 74,0 & 31,5 & 3,6 & 48,9 & 18,3 & 102,3 & 70 & 42,5 \\
\hline \multirow[t]{2}{*}{$10-20$} & SPDR & 5,5 & 29 & 43,1 & 33,5 & 3,7 & 39,6 & 14,7 & 91,5 & 63 & 35,7 \\
\hline & SPDC & 5,4 & 24 & 41,3 & 31,7 & 1,8 & 39,8 & 15,5 & 88,9 & 64 & 33,9 \\
\hline
\end{tabular}

SPDR: sistema plantio direto recém-implantado; SPDC: sistema plantio direto consolidado; MO: matéria orgânica; CTC: capacidade de troca de cátions; e V: saturação por bases.

água destilada, secado em estufa de ventilação forçada de ar a $60-70{ }^{\circ} \mathrm{C}$, por $72 \mathrm{~h}$ e, em seguida, feitas as pesagens. Posteriormente, realizou-se a moagem do material colhido, que foi submetido à análise química, para determinação das concentrações de $\mathrm{N}$, segundo métodos descritos por Malavolta et al. (1997). De posse desses resultados, foram estimadas as quantidades acumuladas desse nutriente por planta, de acordo com os tratamentos.

No florescimento pleno (04/03/2008 e 17/02/2009), foi determinada a população de plantas, contando-se as plantas contidas em duas fileiras de $5 \mathrm{~m}$; coletaram-se 10 plantas por unidade experimental. O material (parte aérea das plantas) foi lavado com água destilada, secado em estufa de ventilação forçada de ar a $60-70{ }^{\circ} \mathrm{C}$, por $72 \mathrm{~h}$, e, em seguida, feitas as pesagens e a transformação dos dados em $\mathrm{kg} \mathrm{ha}^{-1}$ de matéria seca. Posteriormente, realizou-se a moagem do material colhido, que foi submetido à análise química, para determinação das concentrações de N, P, K, Ca, Mg, S, Cu, Fe, Mn e $\mathrm{Zn}$, segundo método descrito por Malavolta et al. (1997). De posse desses resultados, foram estimadas as quantidades acumuladas desses nutrientes por área, de acordo com os tratamentos.

As colheitas foram realizadas em 10/04/2008 e 02/ 04/2009, ou seja, 80 e 79 dias após a emergência (DAE), respectivamente, em que foram determinadas as produtividades de grãos, em $\mathrm{kg} \mathrm{ha}^{-1}$ (13\% de umidade), nas linhas centrais de cada subparcela. Amostras de $100 \mathrm{~g}$ por unidade experimental de grãos foram retiradas e secadas em estufa a $60-70{ }^{\circ} \mathrm{C}$, moídas e submetidas às mesmas análises e determinações descritas anteriormente. De posse desses resultados, foram estimadas as quantidades exportadas desses nutrientes por área.

Os dados foram submetidos à análise de variância e as médias comparadas pelo teste t(DMS) a $5 \%$.

\section{RESULTADOS E DISCUSSÃO}

Não houve feito da interação entre tempo de implantação do SPD e formas de manejo do $\mathrm{N}$ para nenhuma das variáveis estudadas, nos dois anos de cultivo (Quadros 3, 4, 5, 6 e 7).

A produção de matéria seca e a quantidade de $\mathrm{N}$ acumulada na parte aérea das plantas de feijão, no momento da aplicação da adubação de cobertura (estádio $\mathrm{V}_{4}$ ), foram influenciadas apenas pela aplicação de $\mathrm{N}$ em pré-semeadura, nos dois anos de cultivo (Quadro 3). Verificou-se que, independentemente do tempo que o solo encontrava-se sob SPD, a aplicação de $60 \mathrm{~kg} \mathrm{ha}^{-1}$ de $\mathrm{N}$ de forma antecipada, no dia da semeadura, aumentou a produção de matéria seca e o acúmulo de $\mathrm{N}$ na parte aérea; porém, não interferiu na concentração do elemento na planta, o que pode ser consequência de efeito diluição. Destacou-se que, no segundo ano agrícola, as plantas apresentaram maior produção de matéria seca da parte aérea, independentemente do tratamento, e que as diferenças entre os tratamentos que receberam $\mathrm{N}$ em présemeadura e os que não receberam foram menores. Tais resultados, provavelmente, estão relacionados às condições climáticas mais favoráveis e maior disponibilidade de N-mineral no solo (Figura 1, Quadro 2), o que pode ter favorecido o crescimento e a absorção de $\mathrm{N}$ pelas plantas.

A produção de matéria seca da parte aérea das plantas no florescimento não foi influenciada pelo tempo de implantação do SPD, em nenhum dos anos de cultivo (Quadro 4). As características químicas do solo semelhantes e a elevada disponibilidade de nutrientes no SPDR e no SPDC (Quadro 2) justificaram a ausência de diferença no crescimento do feijoeiro. Ressalta-se que as concentrações de $\mathrm{N}$ mineral no solo eram semelhantes no SPDR e SPDC (Quadro 2), e a aplicação de $\mathrm{N}$ em pré-semeadura proporcionou maior 
Quadro 3. Matéria seca, concentração e acúmulo de nitrogênio na parte aérea do feijoeiro, no estádio V4, em razão do tempo de manejo do solo sob sistema plantio direto e da aplicação de $\mathrm{N}$ em pré-semeadura

\begin{tabular}{|c|c|c|c|}
\hline Tratamento & MS & $\begin{array}{c}\text { Concentração } \\
\text { de } \mathbf{N}\end{array}$ & $\begin{array}{l}0 \\
\text { acumulado }\end{array}$ \\
\hline & $\mathrm{g} /$ planta & $\mathrm{g} \mathrm{kg}^{-1}$ & $\mathrm{mg} /$ planta \\
\hline Manejo do solo (M) & & $2007 / 08$ & \\
\hline SPDR & $1,58 \mathrm{a}$ & $44,7 \mathrm{a}$ & $70,8 \mathrm{a}$ \\
\hline SPDC & $1,14 \mathrm{a}$ & $46,2 \mathrm{a}$ & $52,4 \mathrm{a}$ \\
\hline $\mathrm{CV}(\%)$ & 31,4 & 8,3 & 21,1 \\
\hline \multicolumn{4}{|l|}{ Nitrogênio (N) } \\
\hline T0: sem aplicação & $0,98 \mathrm{~b}$ & $45,2 \mathrm{a}$ & $43,9 \mathrm{~b}$ \\
\hline T1: pré-semeadura & $1,75 \mathrm{a}$ & $45,8 \mathrm{a}$ & $79,3 \mathrm{a}$ \\
\hline $\mathrm{CV}(\%)$ & 11,7 & 9,8 & 17,7 \\
\hline Interação $\mathrm{M}$ x N & $\mathrm{ns}$ & $\mathrm{ns}$ & $\mathrm{ns}$ \\
\hline \multicolumn{4}{|c|}{ Manejo do solo (M)2008/09 } \\
\hline SPDR & $1,97 \mathrm{a}$ & $34,1 \mathrm{a}$ & $67,1 \mathrm{a}$ \\
\hline SPDC & $1,78 \mathrm{a}$ & 33,8 a & $60,3 \mathrm{a}$ \\
\hline CV (\%) & 15,5 & 11,7 & 21,6 \\
\hline \multicolumn{4}{|l|}{ Nitrogênio (N) } \\
\hline T0: sem aplicação & $1,52 \mathrm{~b}$ & $33,8 \mathrm{a}$ & $51,3 \mathrm{~b}$ \\
\hline T1: pré-semeadura & $2,23 \mathrm{a}$ & $34,1 \mathrm{a}$ & $76,1 \mathrm{a}$ \\
\hline $\mathrm{CV}(\%)$ & 13,5 & 10,7 & 13,1 \\
\hline Interação M x N & $\mathrm{ns}$ & $\mathrm{ns}$ & $\mathrm{ns}$ \\
\hline
\end{tabular}

Médias seguidas de mesma letra, na coluna dentro de cada fator, não diferem estatisticamente pelo teste $\mathrm{t}$ a $5 \%$. ns: não significativo a $5 \%$ pelo teste F; SPDR: sistema plantio direto recém-implantado; SPDC: sistema plantio direto consolidado; T0: controle (sem aplicação de N); e T1: $60 \mathrm{~kg} \mathrm{ha}^{-1}$ de N antecipado na pré-semeadura da cultura do feijão.

produção de matéria seca no feijoeiro, em ambos os anos de cultivo (Quadro 4).

Em um estudo sobre a adubação nitrogenada no feijoeiro cultivado em SPD e preparo convencional não foi verificado efeito do manejo do solo sobre a produção de matéria seca do feijoeiro; houve resposta à adubação nitrogenada nos dois sistemas de cultivo, sendo essa resposta a maiores doses no SPD (Farinelli et al., 2006). Portanto, o feijoeiro necessitou de $\mathrm{N}$ para seu crescimento inicial, principalmente quando cultivado em SPD, em sucessão a gramíneas (Carvalho et al., 2001; Bordin et al., 2003; Kluthcouski et al., 2005).

As concentrações de nutrientes na parte aérea do feijoeiro não sofreram efeito do tempo de implantação do SPD (Quadro 4), contudo o manejo do N influenciou sua concentração na parte aérea do feijoeiro no segundo ano de cultivo, com o maior valor para a aplicação em pré-semeadura e em cobertura, ou seja, $120 \mathrm{~kg} \mathrm{ha}^{-1}$ de N. A aplicação de $60 \mathrm{~kg} \mathrm{ha}^{-1}$ de $\mathrm{N}$, em présemeadura ou em cobertura em $\mathrm{V}_{4}$, proporcionou concentrações intermediárias de $\mathrm{N}$ na parte aérea. Apesar das maiores concentrações de $\mathrm{N}$ mineral no solo no segundo ano (Quadro 2), a produção de matéria seca e as concentrações de $\mathrm{N}$ na parte aérea foram menores que no primeiro ano, provavelmente em razão da menor radiação solar, ocasionada pela melhor e maior distribuição das precipitações pluviais entre a semeadura e o florescimento (Figura 1), ou seja, maior nebulosidade e talvez maior lixiviação de $\mathrm{N}$ no solo, 0 que pode ter limitado o crescimento e absorção de $\mathrm{N}$ pelas plantas (Fernandes et al., 2006; Righi \& Bernardes, 2008). Estes resultados estão de acordo com os relatados por Farinelli et al. (2006), na mesma localidade.

As concentrações de $\mathrm{P}$ e Kna parte aérea do feijoeiro foram influenciadas pelo manejo do $\mathrm{N}$ apenas no segundo ano de cultivo (Quadro 4). A aplicação de $\mathrm{N}$ em pré-semeadura proporcionou as menores concentrações de $\mathrm{P}$ e K, porém, no caso do $\mathrm{P}$, diferiu apenas do tratamento com aplicação de $\mathrm{N}$ em cobertura e em pré-semeadura e cobertura e, no caso do $\mathrm{K}$, divergiu apenas do tratamento com aplicação de $\mathrm{N}$ em pré-semeadura e cobertura. Esses resultados provavelmente estão relacionados com um efeito de diluição, já que o tratamento com aplicação de $\mathrm{N}$ em pré-semeadura proporcionou maior produção de matéria seca.

No ano agrícola 2007/08, a aplicação de N em présemeadura também proporcionou menores concentrações de $\mathrm{Ca}, \mathrm{Mg}$, S e Zn, especialmente em comparação com o tratamento que recebeu $\mathrm{N}$ apenas em cobertura no estádio $\mathrm{V}_{4}$ da cultura do feijão (Quadro 4). Contudo, a maior concentração de $\mathrm{Cu}$ foi observada no tratamento com aplicação de $\mathrm{N}$ apenas em présemeadura, que diferiu do tratamento com aplicação de $\mathrm{N}$ em duas épocas (T3). A aplicação de $120 \mathrm{~kg} \mathrm{ha}^{-1}$ de $\mathrm{N}$ (pré-semeadura + cobertura) proporcionou concentração de $\mathrm{Mg}$ na parte aérea do feijoeiro significativamente maior que no controle. No ano agrícola 2008/09, a aplicação de $\mathrm{N}$ na pré-semeadura e em cobertura proporcionou maiores concentrações de $\mathrm{Mg}$ e $\mathrm{Zn}$ que quando esse elemento foi aplicado somente em pré-semeadura e com ausência de adubação nitrogenada. A aplicação de $\mathrm{N}$ em présemeadura elevou a concentração de $\mathrm{S}$ a valor maior que os obtidos com o fornecimento de $\mathrm{N}$ em duas épocas (T3). Já as concentrações de Fe foram maiores nos tratamentos que não receberam $\mathrm{N}$ em pré-semeadura.

O tempo que o solo foi manejado sob SPD não teve influência nas quantidades de nutrientes extraídas pela cultura do feijão, nos dois anos de cultivo (Quadro 5). De maneira geral, a maior produção de matéria seca nos tratamentos que receberam aplicação de $\mathrm{N}$ em pré-semeadura (Quadro 4) refletiu em maiores quantidade de nutrientes acumuladas no feijoeiro. A maior disponibilidade de $\mathrm{N}$ para o feijoeiro na fase inicial de desenvolvimento provavelmente causou maior crescimento radicular e, com isso, maior absorção desses nutrientes (Raij, 1991; Marschner, 1995).

O cultivar Pérola apresentou, nos dois anos de cultivo, a seguinte ordem decrescente de exigência de 
Quadro 4. Matéria seca e concentração de nutrientes na parte aérea do feijoeiro, no estádio $\mathbf{R}_{6}$, em razão do tempo de manejo do solo sob sistema plantio direto e da aplicação de $\mathbf{N}$

\begin{tabular}{|c|c|c|c|c|c|c|c|c|c|c|c|}
\hline Tratamento & MS & $\mathbf{N}$ & $\mathbf{P}$ & $\mathbf{K}$ & $\mathbf{C a}$ & $\mathbf{M g}$ & $\mathbf{S}$ & $\mathbf{C u}$ & $\mathbf{F e}$ & Mn & Zn \\
\hline & $\mathrm{kg} \mathrm{ha} \mathrm{h}^{-1}$ & & & $-\mathrm{g} \mathrm{k}_{\mathrm{z}}$ & $\mathrm{s}^{-1}$ & & & & $\mathrm{mg}$ & $\mathrm{kg}^{-1}$ & \\
\hline Manejo do solo (M) & & & & & & $2007 / 08$ & & & & & \\
\hline SPDR & $2.173 \mathrm{a}$ & $30,2 \mathrm{a}$ & $2,8 \mathrm{a}$ & $16,9 \mathrm{a}$ & $18,3 \mathrm{a}$ & $4,5 \mathrm{a}$ & $1,5 \mathrm{a}$ & $49,5 \mathrm{a}$ & $157,4 \mathrm{a}$ & 86,6 a & 27,6 a \\
\hline SPDC & $2.161 \mathrm{a}$ & $31,5 \mathrm{a}$ & $2,6 \mathrm{a}$ & $16,5 \mathrm{a}$ & $16,8 \mathrm{a}$ & $4,8 \mathrm{a}$ & $1,5 \mathrm{a}$ & $50,7 \mathrm{a}$ & $155,5 \mathrm{a}$ & 94,9 a & $28,8 \mathrm{a}$ \\
\hline $\mathrm{CV}(\%)$ & 18,4 & 18,5 & 12,8 & 17,6 & 9,8 & 18,6 & 9,4 & 15,0 & 27,7 & 12,9 & 29,7 \\
\hline \multicolumn{12}{|l|}{ Nitrogênio (N) } \\
\hline T0: sem aplicação & $1.288 \mathrm{c}$ & $30,1 \mathrm{a}$ & $2,7 \mathrm{a}$ & $15,9 \mathrm{a}$ & $18,0 \mathrm{ab}$ & $4,8 \mathrm{ab}$ & $1,5 \mathrm{ab}$ & $51,5 \mathrm{ab}$ & $154,2 \mathrm{a}$ & $76,6 \mathrm{~b}$ & $26,7 \mathrm{ab}$ \\
\hline T1: pré-semeadura & $2.748 \mathrm{a}$ & $30,8 \mathrm{a}$ & $2,6 \mathrm{a}$ & $17,7 \mathrm{a}$ & $14,8 \mathrm{~b}$ & $4,0 \mathrm{~b}$ & $1,3 \mathrm{~b}$ & $56,1 \mathrm{a}$ & $153,8 \mathrm{a}$ & 97,2 a & $25,3 \mathrm{~b}$ \\
\hline $\mathrm{T} 2$ : estádio $\mathrm{V}_{4}$ & $1.717 \mathrm{~b}$ & $33,4 \mathrm{a}$ & $2,8 \mathrm{a}$ & $16,7 \mathrm{a}$ & $19,2 \mathrm{a}$ & $5,3 \mathrm{a}$ & $1,6 \mathrm{a}$ & $48,2 \mathrm{ab}$ & $162,5 \mathrm{a}$ & $88,3 \mathrm{ab}$ & $30,3 \mathrm{a}$ \\
\hline T3: pré-semeadura $+V_{4}$ & $2.915 \mathrm{a}$ & $29,1 \mathrm{a}$ & $2,8 \mathrm{a}$ & $16,5 \mathrm{a}$ & $18,1 \mathrm{a}$ & $4,6 \mathrm{ab}$ & $1,5 \mathrm{ab}$ & $44,4 \mathrm{~b}$ & $155,5 \mathrm{a}$ & $100,8 \mathrm{a}$ & 30,6 a \\
\hline $\mathrm{CV}(\%)$ & 13,3 & 15,9 & 8,2 & 11,6 & 17,8 & 24,6 & 16,6 & 18,9 & 19,6 & 14,5 & 13,6 \\
\hline Interação M x N & $\mathrm{ns}$ & $\mathrm{ns}$ & $\mathrm{ns}$ & $\mathrm{ns}$ & $\mathrm{ns}$ & $\mathrm{ns}$ & $\mathrm{ns}$ & ns & $\mathrm{ns}$ & $\mathrm{ns}$ & $\mathrm{ns}$ \\
\hline Manejo do solo (M) & & & & & & $2008 / 09$ & & & & & \\
\hline SPDR & $1.498 \mathrm{a}$ & $21,7 \mathrm{a}$ & $3,3 \mathrm{a}$ & 16,9 a & $19,2 \mathrm{a}$ & $5,2 \mathrm{a}$ & $2,2 \mathrm{a}$ & $15,1 \mathrm{a}$ & $122,6 \mathrm{a}$ & $75,3 \mathrm{a}$ & $28,8 \mathrm{a}$ \\
\hline SPDC & $1.545 \mathrm{a}$ & $22,1 \mathrm{a}$ & $3,4 \mathrm{a}$ & $15,9 \mathrm{a}$ & $19,0 \mathrm{a}$ & $5,1 \mathrm{a}$ & $2,1 \mathrm{a}$ & $15,0 \mathrm{a}$ & $119,8 \mathrm{a}$ & 69,6 a & $27,7 \mathrm{a}$ \\
\hline CV (\%) & 8,0 & 6,4 & 9,4 & 13,7 & 10,4 & 25,1 & 12,7 & 16,3 & 11,7 & 32,5 & 9,6 \\
\hline \multicolumn{12}{|l|}{ Nitrogênio (N) } \\
\hline T0: sem aplicação & $1.243 \mathrm{c}$ & $20,0 \mathrm{c}$ & $3,3 \mathrm{ab}$ & $15,9 \mathrm{~b}$ & $18,2 \mathrm{a}$ & $4,8 \mathrm{~b}$ & $2,1 \mathrm{ab}$ & $15,1 \mathrm{a}$ & $134,5 \mathrm{a}$ & $78,0 \mathrm{a}$ & $26,8 \mathrm{bc}$ \\
\hline T1: pré-semeadura & $1.742 \mathrm{a}$ & $22,0 \mathrm{~b}$ & $3,2 \mathrm{~b}$ & $15,7 \mathrm{~b}$ & $19,1 \mathrm{a}$ & $4,8 \mathrm{~b}$ & $2,3 \mathrm{a}$ & $14,2 \mathrm{a}$ & $104,6 \mathrm{~b}$ & 64,9 a & $23,9 \mathrm{c}$ \\
\hline $\mathrm{T} 2$ : estádio $\mathrm{V}_{4}$ & $1.463 \mathrm{bc}$ & $21,1 \mathrm{bc}$ & $3,5 \mathrm{a}$ & $16,6 \mathrm{ab}$ & $20,3 \mathrm{a}$ & $5,4 \mathrm{ab}$ & $2,1 \mathrm{ab}$ & $14,7 \mathrm{a}$ & $140,4 \mathrm{a}$ & 76,6 a & $29,5 \mathrm{ab}$ \\
\hline $\mathrm{T} 3$ : pré-semeadura $+\mathrm{V}_{4}$ & $1.640 \mathrm{ab}$ & 24,4 a & $3,5 \mathrm{a}$ & $17,7 \mathrm{a}$ & $18,7 \mathrm{a}$ & $5,6 \mathrm{a}$ & $1,9 \mathrm{~b}$ & $16,1 \mathrm{a}$ & $105,1 \mathrm{~b}$ & $70,3 \mathrm{a}$ & $32,7 \mathrm{a}$ \\
\hline CV (\%) & 16,5 & 5,5 & 6,6 & 7,8 & 17,5 & 14,2 & 12,9 & 28,9 & 24,8 & 23,5 & 16,3 \\
\hline Interação $\mathrm{M}$ x N & $\mathrm{ns}$ & $\mathrm{ns}$ & $\mathrm{ns}$ & $\mathrm{ns}$ & $\mathrm{ns}$ & $\mathrm{ns}$ & $\mathrm{ns}$ & $\mathrm{ns}$ & $\mathrm{ns}$ & $\mathrm{ns}$ & $\mathrm{ns}$ \\
\hline
\end{tabular}

Médias seguidas de mesma letra, na coluna dentro de cada fator, não diferem estatisticamente pelo teste t a $5 \%$. ns: não significativo a $5 \%$ pelo teste F; SPDR: sistema plantio direto recém-implantado; SPDC: sistema plantio direto consolidado; T0: controle (sem aplicação de N); T1: $60 \mathrm{~kg} \mathrm{ha}^{-1}$ de N antecipado na pré-semeadura da cultura do feijão; T2: $60 \mathrm{~kg}$ ha ${ }^{-1}$ de $\mathrm{N}$ em cobertura no estádio $\mathrm{V}_{4}$ da cultura do feijão; e T3: $60 \mathrm{~kg} \mathrm{ha}^{-1}$ na pré-semeadura $+60 \mathrm{~kg} \mathrm{ha}^{-1}$ em cobertura no estádio $\mathrm{V}_{4}$.

macronutrientes no período de florescimento: $\mathrm{N}>\mathrm{Ca}$ $>\mathrm{K}>\mathrm{Mg}>\mathrm{P}>\mathrm{S}$ (Quadro 5), diferente da obtida por Vieira et al. (2009) em SPD: $\mathrm{N}>\mathrm{K}>\mathrm{Ca}>\mathrm{P}>\mathrm{Mg}>$ $\mathrm{S}$. Essa divergência de resultados pode ser explicada por diferenças varietais, no manejo da cultura e nos níveis e quantidades de nutrientes no solo aplicados por meio da adubação. O maior acúmulo de Ca do que de $\mathrm{K}$ neste experimento pode estar relacionado à elevada disponibilidade de Ca no solo (Quadro 2).

Com relação ao acúmulo de micronutrientes, os maiores acúmulos foram de $\mathrm{Fe}$ e $\mathrm{Mn}$, nos dois anos de cultivo (Quadro 5). No entanto, no primeiro ano, as quantidades de $\mathrm{Cu}$ acumuladas foram maiores que as de Zn, contrariamente ao observado no segundo ano. Tais resultados são explicados pela aplicação de fungicida óxido cuproso uma semana antes da coleta de plantas, no primeiro ano. Barbosa Filho \& Silva (2000) também observaram maiores acúmulos de Fe e Mn na parte aérea do feijoeiro, seguidos de menores quantidades de $\mathrm{Zn}$ e, especialmente, de $\mathrm{Cu}$.

O tempo de implantação do SPD não influenciou a produtividade de grãos de feijão, em nenhum dos anos de cultivo (Quadro 6), o que pode ser justificado pelas condições semelhantes de fertilidade do solo e pela ausência de efeito no crescimento vegetativo e na absorção de nutrientes pelas plantas, em ambos os tratamentos (Quadros 2, 3, 4 e 5).

Independentemente do tempo que o solo estava sob SPD, a aplicação de $\mathrm{N}$ incrementou a produtividade de grãos do feijoeiro, nos dois anos agrícolas (Quadro 6). Em 2007/08, a maior produtividade de grãos foi obtida com a aplicação de $\mathrm{N}$ em pré-semeadura e em cobertura, ou seja, $120 \mathrm{~kg} \mathrm{ha}^{-1}$, com valores intermediários sendo obtidos quando foi realizada apenas uma aplicação de $\mathrm{N}\left(60 \mathrm{~kg} \mathrm{ha}^{-1}\right)$. No ano agrícola de 2008/09, não houve diferença entre os tratamentos que receberam aplicação de $\mathrm{N}$, porém apenas os tratamentos que receberam o nutriente em cobertura produziram significativamente mais que 0 controle (sem aplicação de N), o que reforça a hipótese de que a maior precipitação pluvial até o florescimento da cultura, no segundo ano (Figura 1), pode ter favorecido a lixiviação de $\mathrm{N}$.

As concentrações de $\mathrm{P}$ e K nos grãos de feijão, no 
Quadro 5. Nutrientes acumulados na parte aérea do feijoeiro, no estádio $R_{6}$, em razão do tempo de manejo do solo sob sistema plantio direto e da aplicação de $\mathbf{N}$

\begin{tabular}{|c|c|c|c|c|c|c|c|c|c|c|}
\hline Tratamento & $\mathbf{N}$ & $\mathbf{P}$ & $\mathbf{K}$ & $\mathbf{C a}$ & Mg & $\mathbf{S}$ & $\mathbf{C u}$ & $\mathbf{F e}$ & Mn & $\mathbf{Z n}$ \\
\hline & \multicolumn{6}{|c|}{$-\mathrm{kg} \mathrm{ha}^{-1}$} & \multicolumn{4}{|c|}{$\mathrm{g} \mathrm{ha}^{-1}$} \\
\hline Manejo do solo (M) & \multicolumn{10}{|c|}{$2007 / 08$} \\
\hline SPDR & $65,6 \mathrm{a}$ & $6,0 \mathrm{a}$ & $36,0 \mathrm{a}$ & $39,5 \mathrm{a}$ & $9,6 \mathrm{a}$ & $3,1 \mathrm{a}$ & $106,3 \mathrm{a}$ & 337,6 a & $196,0 \mathrm{a}$ & $60,8 \mathrm{a}$ \\
\hline SPDC & $67,7 \mathrm{a}$ & $5,7 \mathrm{a}$ & $36,7 \mathrm{a}$ & $35,0 \mathrm{a}$ & $10,0 \mathrm{a}$ & $3,1 \mathrm{a}$ & $111,7 \mathrm{a}$ & 334,2 a & $210,0 \mathrm{a}$ & $62,4 \mathrm{a}$ \\
\hline $\mathrm{CV}(\%)$ & 34,2 & 28,1 & 14,0 & 21,5 & 33,6 & 23,5 & 23,2 & 33,6 & 28,8 & 45,3 \\
\hline \multicolumn{11}{|l|}{ Nitrogênio (N) } \\
\hline T0: sem aplicação & $39,2 \mathrm{c}$ & $3,5 \mathrm{c}$ & $20,6 \mathrm{c}$ & $23,3 \mathrm{c}$ & $6,2 \mathrm{c}$ & $1,9 \mathrm{~b}$ & $66,8 \mathrm{~b}$ & $197,6 \mathrm{~b}$ & $98,1 \mathrm{c}$ & $34,2 \mathrm{~d}$ \\
\hline T1: pré-semeadura & $84,7 \mathrm{a}$ & $7,2 \mathrm{a}$ & $48,4 \mathrm{a}$ & $40,1 \mathrm{~b}$ & $10,7 \mathrm{~b}$ & $3,6 \mathrm{a}$ & $154,8 \mathrm{a}$ & $421,0 \mathrm{a}$ & $267,1 \mathrm{a}$ & $70,3 \mathrm{~b}$ \\
\hline $\mathrm{T} 2$ : estádio $\mathrm{V}_{4}$ & $58,4 \mathrm{~b}$ & $4,8 \mathrm{~b}$ & $28,6 \mathrm{~b}$ & $32,9 \mathrm{~b}$ & $9,1 \mathrm{~b}$ & $2,7 \mathrm{~b}$ & $81,5 \mathrm{~b}$ & $272,0 \mathrm{~b}$ & $151,9 \mathrm{~b}$ & $52,9 \mathrm{c}$ \\
\hline $\mathrm{T} 3$ : pré-semeadura $+\mathrm{V}_{4}$ & $84,2 \mathrm{a}$ & $8,0 \mathrm{a}$ & 47,9 a & $52,7 \mathrm{a}$ & $13,4 \mathrm{a}$ & $4,3 \mathrm{a}$ & 132,9 a & $453,0 \mathrm{a}$ & $294,0 \mathrm{a}$ & 89,0 a \\
\hline $\mathrm{CV}(\%)$ & 20,2 & 14,6 & 17,3 & 18,4 & 18,5 & 25,5 & 30,3 & 23,3 & 20,0 & 18,6 \\
\hline Interação $\mathrm{M}$ x N & $\mathrm{ns}$ & $\mathrm{ns}$ & $\mathrm{ns}$ & ns & $\mathrm{ns}$ & $\mathrm{ns}$ & $\mathrm{ns}$ & $\mathrm{ns}$ & ns & $\mathrm{ns}$ \\
\hline Manejo do solo (M) & \multicolumn{10}{|c|}{$2008 / 09$} \\
\hline SPDR & 33,5 a & $5,0 \mathrm{a}$ & 25,4 a & $29,0 \mathrm{a}$ & $7,9 \mathrm{a}$ & $3,2 \mathrm{a}$ & $22,4 \mathrm{a}$ & $180,0 \mathrm{a}$ & $112,2 \mathrm{a}$ & $43,3 \mathrm{a}$ \\
\hline SPDC & 33,7 a & $5,3 \mathrm{a}$ & $24,6 \mathrm{a}$ & $29,3 \mathrm{a}$ & $7,9 \mathrm{a}$ & $3,2 \mathrm{a}$ & $22,9 \mathrm{a}$ & 180,9 a & $105,8 \mathrm{a}$ & $42,4 \mathrm{a}$ \\
\hline $\mathrm{CV}(\%)$ & 12,3 & 11,4 & 14,1 & 11,2 & 22,5 & 18,0 & 22,5 & 9,8 & 31,1 & 8,3 \\
\hline \multicolumn{11}{|l|}{ Nitrogênio (N) } \\
\hline T0: sem aplicação & $24,9 \mathrm{~b}$ & $4,1 \mathrm{~b}$ & $19,7 \mathrm{~b}$ & $22,4 \mathrm{~b}$ & $5,9 \mathrm{~b}$ & $2,6 \mathrm{~b}$ & $18,7 \mathrm{~b}$ & $167,5 \mathrm{a}$ & 96,0 a & $33,3 \mathrm{c}$ \\
\hline T1: pré-semeadura & 38,5 a & $5,6 \mathrm{a}$ & $27,4 \mathrm{a}$ & $33,4 \mathrm{a}$ & $8,3 \mathrm{a}$ & $4,0 \mathrm{a}$ & $24,4 \mathrm{ab}$ & $178,7 \mathrm{a}$ & $112,4 \mathrm{a}$ & $41,4 \mathrm{bc}$ \\
\hline T2: estádio $\mathrm{V}_{4}$ & $31,0 \mathrm{~b}$ & $5,1 \mathrm{a}$ & $24,1 \mathrm{ab}$ & $30,0 \mathrm{ab}$ & $8,0 \mathrm{a}$ & $3,0 \mathrm{~b}$ & $21,4 \mathrm{ab}$ & 199,8 a & 109,6 a & $43,0 \mathrm{~b}$ \\
\hline T3: pré-semeadura $+\mathrm{V}_{4}$ & 40,0 a & $5,7 \mathrm{a}$ & $28,6 \mathrm{a}$ & $30,9 \mathrm{a}$ & $9,3 \mathrm{a}$ & $3,2 \mathrm{~b}$ & $26,0 \mathrm{a}$ & $175,8 \mathrm{a}$ & 117,9 a & $53,7 \mathrm{a}$ \\
\hline $\mathrm{CV}(\%)$ & 18,9 & 17,5 & 20,0 & 25,2 & 23,5 & 20,0 & 28,8 & 28,0 & 28,4 & 21,2 \\
\hline Interação $\mathrm{M}$ x N & $\mathrm{ns}$ & $\mathrm{ns}$ & $\mathrm{ns}$ & $\mathrm{ns}$ & $\mathrm{ns}$ & $\mathrm{ns}$ & $\mathrm{ns}$ & $\mathrm{ns}$ & $\mathrm{ns}$ & $\mathrm{ns}$ \\
\hline
\end{tabular}

Médias seguidas de mesma letra, na coluna dentro de cada fator, não diferem estatisticamente pelo teste t a $5 \%$; ns: não significativo a $5 \%$ pelo teste F; SPDR: sistema plantio direto recém-implantado; SPDC: sistema plantio direto consolidado; T0: controle (sem aplicação de N); T1: $60 \mathrm{~kg} \mathrm{ha}^{-1}$ de N antecipado na pré-semeadura da cultura do feijão; T2: $60 \mathrm{~kg}$ ha-1 de $\mathrm{N}$ em cobertura no estádio $\mathrm{V}_{4}$ da cultura do feijão; e T3: $60 \mathrm{~kg} \mathrm{ha}^{-1}$ na pré-semeadura $+60 \mathrm{~kg} \mathrm{ha}^{-1}$ em cobertura no estádio $\mathrm{V}_{4}$.

segundo ano de cultivo, foram influenciadas pelo tempo de adoção do SPD (Quadro 6). O SPDC proporcionou maior concentração de $P$ nos grãos, no segundo ano, provavelmente em razão da sua maior disponibilidade no solo (Quadro 2). O não revolvimento e a gradual decomposição dos restos de culturas na superfície do solo resultaram em menor perda de solo por erosão, menor mistura dos fertilizantes com o solo e, maior acúmulo principalmente de $\mathrm{P}$ na camada superficial, além da manutenção desse nutriente em forma disponível por maior período por causa da competição de compostos orgânicos pelos sítios de adsorção (Rheinheimer et al., 1998). O SPDC também proporcionou menores concentrações de $\mathrm{K}$ nos grãos do feijoeiro que o SPDR, provavelmente em razão das menores concentrações de $\mathrm{K}$ e maiores de $\mathrm{Ca}$ e $\mathrm{Mg}$ no solo manejado há maior tempo sem revolvimento.

Apesar de ter incrementado significativamente a produtividade de grãos do feijoeiro, nos dois anos agrícolas, a aplicação de $\mathrm{N}$ influenciou apenas as concentrações de Mn e Zn nos grãos, em 2007/08, e de Mg, Mn e Zn, em 2008/09 (Quadro 6). A aplicação de $\mathrm{N}$ apenas em cobertura proporcionou concentração de
Mg nos grãos significativamente maior que no controle. No caso do Mn, as maiores concentrações foram obtidas nos grãos produzidos com aplicação de $\mathrm{N}$ apenas em cobertura ou em pré-semeadura e em cobertura, no primeiro ano; e no controle e com a aplicação de $\mathrm{N}$ apenas em cobertura, no segundo ano. Quanto ao $\mathrm{Zn}$, a aplicação de $\mathrm{N}$ apenas em présemeadura proporcionou as menores concentrações de Zn, em ambos os anos.

Estudos voltados à avaliação das concentrações dos nutrientes nos grãos de feijão em razão da adubação nitrogenada e dos sistemas de cultivo são raros na literatura, porém são muito importantes para avaliar a qualidade nutricional dos grãos de feijão. Em um estudo sobre a produtividade e qualidade nutricional de cultivares de feijão submetidos a diferentes adubações, não foi verificado acréscimo nas concentrações de $\mathrm{P}, \mathrm{K}, \mathrm{Ca}, \mathrm{Mg}$, S e Zn nos grãos do feijoeiro com a aplicação de $\mathrm{N}$ na semeadura ou em cobertura; no entanto, as concentrações de $\mathrm{N}, \mathrm{Cu}, \mathrm{Fe}$ e Mn foram incrementadas (Andrade et al., 2004).

As quantidades de $\mathrm{P}, \mathrm{Se} \mathrm{Zn}$ exportadas pelos grãos de feijão foram maiores no SPDC, no segundo ano de 
Quadro 6. Produtividade e concentração de nutrientes nos grãos do feijoeiro em razão do tempo de manejo do solo sob sistema plantio direto e da aplicação de $\mathbf{N}$

\begin{tabular}{|c|c|c|c|c|c|c|c|c|c|c|c|}
\hline Tratamento & Prod. & $\mathbf{N}$ & $\mathbf{P}$ & $\mathbf{K}$ & $\mathbf{C a}$ & $\mathbf{M g}$ & $\mathbf{S}$ & $\mathbf{C u}$ & $\mathbf{F e}$ & Mn & $\mathbf{Z n}$ \\
\hline & $\mathrm{kg} \mathrm{ha}^{-1}$ & & & g l & $s^{-1}$ & & & & mg & $g^{-1}$ & \\
\hline Manejo do solo (M) & & & & & & $2007 / 08$ & & & & & \\
\hline SPDR & $2.085 \mathrm{a}$ & $32,7 \mathrm{a}$ & $8,0 \mathrm{a}$ & $18,8 \mathrm{a}$ & $2,9 \mathrm{a}$ & $2,8 \mathrm{a}$ & $1,5 \mathrm{a}$ & $7,0 \mathrm{a}$ & 74,6 a & $18,6 \mathrm{a}$ & $47,4 \mathrm{a}$ \\
\hline SPDC & $2.228 \mathrm{a}$ & $32,9 \mathrm{a}$ & $6,7 \mathrm{a}$ & $19,4 \mathrm{a}$ & $2,8 \mathrm{a}$ & $3,1 \mathrm{a}$ & $1,1 \mathrm{a}$ & $6,8 \mathrm{a}$ & 71,9 a & $17,8 \mathrm{a}$ & $48,0 \mathrm{a}$ \\
\hline $\mathrm{CV}(\%)$ & 19,2 & 12,9 & 19,7 & 5,1 & 14,1 & 21,4 & 39,5 & 14,5 & 16,4 & 14,4 & 5,3 \\
\hline \multicolumn{12}{|l|}{ Nitrogênio (N) } \\
\hline T0: sem aplicação & $1.729 \mathrm{c}$ & $31,8 \mathrm{a}$ & $7,6 \mathrm{a}$ & $20,1 \mathrm{a}$ & $3,0 \mathrm{a}$ & $3,2 \mathrm{a}$ & $1,2 \mathrm{a}$ & $7,1 \mathrm{a}$ & $76,1 \mathrm{a}$ & $17,3 \mathrm{~b}$ & $47,8 \mathrm{ab}$ \\
\hline T1: pré-semeadura & $2.177 \mathrm{~b}$ & $32,2 \mathrm{a}$ & $7,3 \mathrm{a}$ & $18,7 \mathrm{a}$ & $2,7 \mathrm{a}$ & $2,7 \mathrm{a}$ & $1,4 \mathrm{a}$ & $6,5 \mathrm{a}$ & 70,6 a & $18,1 \mathrm{ab}$ & $46,0 \mathrm{~b}$ \\
\hline $\mathrm{T} 2$ : estádio $\mathrm{V}_{4}$ & $2.037 \mathrm{~b}$ & $33,0 \mathrm{a}$ & $6,7 \mathrm{a}$ & $18,8 \mathrm{a}$ & $2,8 \mathrm{a}$ & $2,9 \mathrm{a}$ & $1,3 \mathrm{a}$ & 6,9 a & $73,1 \mathrm{a}$ & $18,5 \mathrm{a}$ & $48,8 \mathrm{a}$ \\
\hline $\mathrm{T} 3$ : pré-semeadura $+\mathrm{V}_{4}$ & $2.684 \mathrm{a}$ & $34,3 \mathrm{a}$ & $7,8 \mathrm{a}$ & $18,9 \mathrm{a}$ & $2,8 \mathrm{a}$ & $3,2 \mathrm{a}$ & $1,3 \mathrm{a}$ & $7,1 \mathrm{a}$ & $73,2 \mathrm{a}$ & $18,8 \mathrm{a}$ & $48,2 \mathrm{a}$ \\
\hline $\mathrm{CV}(\%)$ & 13,3 & 10,8 & 19,9 & 6,8 & 29,9 & 20,5 & 39,7 & 16,5 & 15,3 & 5,8 & 4,3 \\
\hline Interação M x N & ns & $\mathrm{ns}$ & $\mathrm{ns}$ & $\mathrm{ns}$ & ns & $\mathrm{ns}$ & $\mathrm{ns}$ & $\mathrm{ns}$ & $\mathrm{ns}$ & $\mathrm{ns}$ & $\mathrm{ns}$ \\
\hline Manejo do solo (M) & & & & & & 2008/09 & & & & & \\
\hline SPDR & $1.352 \mathrm{a}$ & $37,5 \mathrm{a}$ & $7,5 \mathrm{~b}$ & $16,9 \mathrm{a}$ & $2,2 \mathrm{a}$ & $2,6 \mathrm{a}$ & $4,8 \mathrm{a}$ & $7,3 \mathrm{a}$ & 68,9 a & $11,7 \mathrm{a}$ & 25,5 a \\
\hline SPDC & $1.504 \mathrm{a}$ & $39,2 \mathrm{a}$ & $9,0 \mathrm{a}$ & $15,8 \mathrm{~b}$ & $2,0 \mathrm{a}$ & $5,5 \mathrm{a}$ & $4,8 \mathrm{a}$ & $6,2 \mathrm{a}$ & 69,6 a & $10,9 \mathrm{a}$ & $26,0 \mathrm{a}$ \\
\hline $\mathrm{CV}(\%)$ & 12,1 & 4,6 & 7,6 & 2,9 & 25,4 & 15,7 & 6,1 & 26,0 & 8,6 & 15,0 & 12,4 \\
\hline \multicolumn{12}{|l|}{ Nitrogênio (N) } \\
\hline T0T0: sem aplicação & $1.177 \mathrm{~b}$ & 37,9 a & $8,8 \mathrm{a}$ & $15,5 \mathrm{a}$ & $1,9 \mathrm{a}$ & $2,3 \mathrm{~b}$ & $4,8 \mathrm{a}$ & $7,6 \mathrm{a}$ & 72,9 a & $13,8 \mathrm{a}$ & 27,4 a \\
\hline T1: pré-semeadura & $1.353 \mathrm{ab}$ & $37,8 \mathrm{a}$ & $8,7 \mathrm{a}$ & $16,5 \mathrm{a}$ & $2,4 \mathrm{a}$ & $2,6 \mathrm{ab}$ & $4,9 \mathrm{a}$ & $6,2 \mathrm{a}$ & 68,5 a & $9,5 \mathrm{~b}$ & $24,8 \mathrm{~b}$ \\
\hline $\mathrm{T} 2$ : estádio $\mathrm{V}_{4}$ & $1.612 \mathrm{a}$ & $37,6 \mathrm{a}$ & $8,2 \mathrm{a}$ & $16,7 \mathrm{a}$ & $2,1 \mathrm{a}$ & $2,7 \mathrm{a}$ & $4,8 \mathrm{a}$ & $6,8 \mathrm{a}$ & $66,3 \mathrm{a}$ & $12,5 \mathrm{a}$ & $25,8 \mathrm{ab}$ \\
\hline T3: pré-semeadura $+\mathrm{V}_{4}$ & $1.569 \mathrm{a}$ & $40,0 \mathrm{a}$ & $7,3 \mathrm{a}$ & $16,5 \mathrm{a}$ & $2,0 \mathrm{a}$ & $2,6 \mathrm{ab}$ & $4,7 \mathrm{a}$ & $6,5 \mathrm{a}$ & 69,4 a & $9,2 \mathrm{~b}$ & $25,0 \mathrm{~b}$ \\
\hline $\mathrm{CV}(\%)$ & 18,1 & 8,2 & 22,4 & 7,8 & 24,7 & 16,3 & 7,1 & 24,5 & 10,5 & 17,8 & 8,7 \\
\hline Interação M x N & $\mathrm{ns}$ & $\mathrm{ns}$ & $\mathrm{ns}$ & $\mathrm{ns}$ & $\mathrm{ns}$ & $\mathrm{ns}$ & $\mathrm{ns}$ & $\mathrm{ns}$ & $\mathrm{ns}$ & $\mathrm{ns}$ & $\mathrm{ns}$ \\
\hline
\end{tabular}

Prod.: produtividade. Médias seguidas de mesma letra, na coluna dentro de cada fator, não diferem estatisticamente pelo teste $\mathrm{t}$ a $5 \%$; ns: não significativo a $5 \%$ pelo teste F; SPDR: sistema plantio direto recém-implantado; SPDC: sistema plantio direto consolidado; T0: controle (sem aplicação de N); T1: $60 \mathrm{~kg} \mathrm{ha}^{-1}$ de N antecipado na pré-semeadura da cultura do feijão; T2: $60 \mathrm{~kg}$ ha ${ }^{-1}$ de $\mathrm{N}$ em cobertura no estádio $\mathrm{V}_{4}$ da cultura do feijão; e T3: $60 \mathrm{~kg} \mathrm{ha}^{-1}$ na pré-semeadura $+60 \mathrm{~kg} \mathrm{ha}^{-1}$ em cobertura no estádio $\mathrm{V}_{4}$.

cultivo (Quadro 7). Esses resultados são explicados pela maior concentração nos grãos, no caso do $\mathrm{P}$, e pelo efeito aditivo de pequenos aumentos, apesar de não significativos, na produtividade de grãos e nas concentrações de S e Zn nos grãos observados nos SPDC (Quadro 6).

A maior exportação de $\mathrm{N}$ foi verificada no tratamento que recebeu aplicação de $60 \mathrm{~kg} \mathrm{ha}^{-1} \mathrm{em}$ pré-semeadura e $60 \mathrm{~kg} \mathrm{ha}^{-1}$ em cobertura, em ambos os anos agrícolas (Quadro 7), por causa das maiores produtividades de grãos e concentrações de $\mathrm{N}$ nos grãos proporcionadas por esse tratamento (Quadro 6). Com relação aos demais nutrientes, em 2007/08, as maiores quantidades exportadas foram observadas com a aplicação de $\mathrm{N}$ em pré-semeadura e em cobertura. Já em 2008/09, de maneira geral, as maiores quantidades de nutrientes exportados foram proporcionadas pela aplicação de $\mathrm{N}$ apenas em cobertura no estádio $\mathrm{V}_{4}$. Ressaltou-se que, como as concentrações de nutrientes nos grãos foram pouco influenciados pelos tratamentos (Quadro 6), a exportação está diretamente relacionada com a produtividade de grãos (Quadro 7).
Os nutrientes exportados pela cultura do feijão, independentemente do tratamento estudado, obedeceram à ordem $\mathrm{N}>\mathrm{K}>\mathrm{P}>\mathrm{Mg}>\mathrm{Ca}>\mathrm{S}>\mathrm{Fe}>\mathrm{Zn}>\mathrm{Mn}>\mathrm{Cu}$, no primeiro ano, e $\mathrm{N}>\mathrm{K}>\mathrm{P}>\mathrm{S}>\mathrm{Mg}>\mathrm{Ca}>\mathrm{Fe}>\mathrm{Zn}>$ $\mathrm{Mn}>\mathrm{Cu}$, no segundo (Quadro 7). A exportação de maior quantidade de S do que de $\mathrm{Mg}$ e $\mathrm{Ca}$, no segundo ano agrícola, deveu-se à utilização de superfosfato simples (fertilizante que contém S) na adubação de semeadura, que elevou expressivamente as concentrações de S nos grãos. Barbosa Filho \& Silva (2000) também relataram maiores exportações de $\mathrm{N}$, K e P, porém a ordem de exportação dos demais nutrientes foi diferente das observadas neste trabalho. Tais divergências são em razão das diferenças ambientais, da fertilidade do solo e dos cultivares utilizados.

\section{CONCLUSÕES}

1. O tempo que o solo permaneceu sob SPD não influenciou a produtividade, a nutrição e a resposta da cultura do feijão ao manejo da adubação nitrogenada. 
Quadro 7. Nutrientes exportados pelos grãos do feijoeiro em razão do tempo de manejo do solo sob sistema plantio direto e da aplicação de $\mathbf{N}$

\begin{tabular}{|c|c|c|c|c|c|c|c|c|c|c|}
\hline Tratamento & $\mathbf{N}$ & $\mathbf{P}$ & $\mathbf{K}$ & $\mathbf{C a}$ & Mg & $\mathbf{S}$ & $\mathbf{C u}$ & $\mathbf{F e}$ & Mn & $\mathbf{Z n}$ \\
\hline & \multicolumn{6}{|c|}{$\mathrm{kg} \mathrm{ha}^{-1}$} & \multicolumn{4}{|c|}{$\mathrm{g} \mathrm{ha}^{-1}$} \\
\hline Manejo do solo (M) & \multicolumn{10}{|c|}{$2007 / 08$} \\
\hline SPDR & 59,6 a & $14,6 \mathrm{a}$ & 33,9 a & $5,2 \mathrm{a}$ & $5,1 \mathrm{a}$ & $2,7 \mathrm{a}$ & $12,5 \mathrm{a}$ & $134,5 \mathrm{a}$ & $33,8 \mathrm{a}$ & $86,0 \mathrm{a}$ \\
\hline SPDC & $64,1 \mathrm{a}$ & 13,0 a & $37,6 \mathrm{a}$ & $5,4 \mathrm{a}$ & $6,1 \mathrm{a}$ & $2,2 \mathrm{a}$ & $13,2 \mathrm{a}$ & $141,3 \mathrm{a}$ & $34,9 \mathrm{a}$ & $93,0 \mathrm{a}$ \\
\hline $\mathrm{CV}(\%)$ & 16,7 & 33,2 & 16,0 & 11,2 & 15,7 & 51,6 & 21,8 & 31,6 & 26,8 & 23,6 \\
\hline \multicolumn{11}{|l|}{ Nitrogênio (N) } \\
\hline T0: sem aplicação & $47,9 \mathrm{c}$ & $11,4 \mathrm{~b}$ & $30,3 \mathrm{~b}$ & $4,4 \mathrm{~b}$ & $4,8 \mathrm{~b}$ & $1,9 \mathrm{~b}$ & $10,6 \mathrm{~b}$ & $116,5 \mathrm{~b}$ & $26,2 \mathrm{c}$ & $71,9 \mathrm{c}$ \\
\hline T1: pré-semeadura & $61,1 \mathrm{~b}$ & $13,6 \mathrm{~b}$ & $35,5 \mathrm{~b}$ & $5,2 \mathrm{ab}$ & $5,1 \mathrm{~b}$ & $2,6 \mathrm{ab}$ & $12,1 \mathrm{~b}$ & $133,5 \mathrm{~b}$ & $34,2 \mathrm{~b}$ & $87,0 \mathrm{~b}$ \\
\hline $\mathrm{T} 2$ : estádio $\mathrm{V}_{4}$ & $58,3 \mathrm{bc}$ & $11,9 \mathrm{~b}$ & $33,3 \mathrm{~b}$ & $5,1 \mathrm{ab}$ & $5,1 \mathrm{~b}$ & $2,3 \mathrm{ab}$ & $12,2 \mathrm{~b}$ & $130,8 \mathrm{~b}$ & $32,9 \mathrm{~b}$ & $86,6 \mathrm{~b}$ \\
\hline T3: pré-semeadura $+\mathrm{V}_{4}$ & $80,2 \mathrm{a}$ & $18,2 \mathrm{a}$ & 43,9 a & $6,6 \mathrm{a}$ & $7,2 \mathrm{a}$ & $3,1 \mathrm{a}$ & $16,6 \mathrm{a}$ & $170,8 \mathrm{a}$ & $43,9 \mathrm{a}$ & $112,5 \mathrm{a}$ \\
\hline CV (\%) & 17,3 & 24,2 & 15,6 & 33,9 & 22,2 & 43,7 & 22,8 & 23,7 & 13,4 & 13,9 \\
\hline Interação M x N & ns & $\mathrm{ns}$ & $\mathrm{ns}$ & $\mathrm{ns}$ & $\mathrm{ns}$ & $\mathrm{ns}$ & $\mathrm{ns}$ & $\mathrm{ns}$ & $\mathrm{ns}$ & $\mathrm{ns}$ \\
\hline Manejo do solo (M) & \multicolumn{10}{|c|}{$2008 / 09$} \\
\hline SPDR & $44,3 \mathrm{a}$ & $8,7 \mathrm{~b}$ & 19,9 a & $2,6 \mathrm{a}$ & $3,1 \mathrm{a}$ & $5,7 \mathrm{~b}$ & $8,0 \mathrm{a}$ & $80,4 \mathrm{a}$ & $13,5 \mathrm{a}$ & $29,9 \mathrm{~b}$ \\
\hline SPDC & $51,7 \mathrm{a}$ & $11,9 \mathrm{a}$ & $20,7 \mathrm{a}$ & $2,6 \mathrm{a}$ & $3,4 \mathrm{a}$ & $6,2 \mathrm{a}$ & $8,7 \mathrm{a}$ & $90,9 \mathrm{a}$ & $14,1 \mathrm{a}$ & $33,9 \mathrm{a}$ \\
\hline $\mathrm{CV}(\%)$ & 9,6 & 10,8 & 11,4 & 32,2 & 21,4 & 7,3 & 30,0 & 20,1 & 11,1 & 9,6 \\
\hline \multicolumn{11}{|l|}{ Nitrogênio (N) } \\
\hline T0: sem aplicação & $39,4 \mathrm{~b}$ & $9,1 \mathrm{a}$ & $15,8 \mathrm{c}$ & $2,0 \mathrm{~b}$ & $2,3 \mathrm{~b}$ & $5,0 \mathrm{~b}$ & $7,8 \mathrm{a}$ & $74,7 \mathrm{~b}$ & $13,7 \mathrm{~b}$ & $28,3 \mathrm{~b}$ \\
\hline T1: pré-semeadura & $44,8 \mathrm{ab}$ & $10,4 \mathrm{a}$ & $19,4 \mathrm{bc}$ & $2,8 \mathrm{ab}$ & $3,2 \mathrm{a}$ & $5,7 \mathrm{ab}$ & $7,3 \mathrm{a}$ & $80,9 \mathrm{ab}$ & $11,4 \mathrm{~b}$ & $29,3 \mathrm{ab}$ \\
\hline $\mathrm{T} 2$ : estádio $\mathrm{V}_{4}$ & $52,7 \mathrm{a}$ & $11,6 \mathrm{a}$ & $23,5 \mathrm{a}$ & $3,0 \mathrm{a}$ & $3,9 \mathrm{a}$ & $6,7 \mathrm{a}$ & $9,5 \mathrm{a}$ & $92,8 \mathrm{a}$ & $17,4 \mathrm{a}$ & $36,0 \mathrm{a}$ \\
\hline $\mathrm{T} 3$ : pré-semeadura $+\mathrm{V}_{4}$ & $55,1 \mathrm{a}$ & $10,0 \mathrm{a}$ & $22,6 \mathrm{ab}$ & $2,7 \mathrm{ab}$ & $3,5 \mathrm{a}$ & $6,4 \mathrm{a}$ & 8,9 a & 94,2 a & $12,6 \mathrm{~b}$ & $33,9 \mathrm{ab}$ \\
\hline CV (\%) & 22,7 & 31,8 & 18,6 & 34,5 & 23,8 & 20,0 & 35,6 & 18,8 & 24,2 & 22,2 \\
\hline Interação $\mathrm{M}$ x N & ns & ns & $\mathrm{ns}$ & ns & ns & $\mathrm{ns}$ & $\mathrm{ns}$ & ns & $\mathrm{ns}$ & ns \\
\hline
\end{tabular}

Médias seguidas de mesma letra, na coluna dentro de cada fator, não diferem estatisticamente pelo teste t a $5 \%$; ns: não significativo a $5 \%$ pelo teste F; SPDR: sistema plantio direto recém-implantado; SPDC: sistema plantio direto consolidado; T0: controle (sem aplicação de N); T1: $60 \mathrm{~kg} \mathrm{ha}^{-1}$ de N antecipado na pré-semeadura da cultura do feijão; T2: 60 $\mathrm{kg} \mathrm{ha}^{-1}$ de $\mathrm{N}$ em cobertura no estádio $\mathrm{V}_{4}$ da cultura do feijão; e T3: $60 \mathrm{~kg}^{\mathrm{ha}}{ }^{-1}$ na pré-semeadura $+60 \mathrm{~kg}$ ha ${ }^{-1}$ em cobertura no estádio $\mathrm{V}_{4}$.

2. A aplicação de $\mathrm{N}$, especialmente em présemeadura, proporcionou maiores acúmulos de matéria seca e nutrientes na parte aérea da cultura do feijão.

3. As concentrações dos nutrientes nos grãos de feijão foram pouco influenciadas pela adubação nitrogenada.

4. As maiores produtividades de grãos e exportações de nutrientes foram causadas pela aplicação de $\mathrm{N}$ em duas épocas (pré-semeadura e em cobertura) ou apenas em cobertura.

\section{AGRADECIMENTOS}

À Fapesp, pela concessão das bolsas de Mestrado (2008/01961-6), ao primeiro autor, e de Iniciação Científica (2008/02426-7, à terceira autora. Ao CNPq, pela concessão de bolsa de Produtividade em Pesquisa ao segundo autor.

\section{LITERATURA CITADA}

ALVES JUNIOR, J.; ANDRADE, M.J.B.; CARVALHO, J.G.; VIEIRA, N.M.B. \& MORA, A.R. Adubação nitrogenada do feijoeiro, em plantio e cobertura em plantio direto e convencional. Ci. Agrotec., 33:943-949, 2009.

AMADO, T.J.C. \& MIELNICZUK, J. Estimativa da adubação nitrogenada para o milho em sistemas de manejo e cultura de cobertura do solo. R. Bras. Ci. Solo, 24:553-560, 2000.

ANDRADE, C.A.B.; PATRONI, S.M.S.; CLEMENTE, E. \& SCAPIM, C.A. Produtividade e qualidade nutricional de cultivares de feijão em diferentes adubações. Ci. Agrotec., 28:1077-1086, 2004

BARBOSA FILHO, M.P. \& SILVA, O.F. Adubação e calagem para o feijoeiro irrigado em solo de Cerrado. Pesq. Agropec. Bras., 35:1317-1324, 2000.

BOER, C.A.; ASSIS, R.A.; SILVA, G.P.; BRAZ, A.J.B.P.; BARROSO, A.L.L.; CARGNELUTTI FILHO, A. \& PIRES, F.R. Ciclagem de nutrientes por plantas de cobertura na entressafra em um solo de cerrado. Pesq. Agropec. Bras., 42:1269-1276, 2007. 
BORDIN, L.; FARINELLI, R.; PENARIOL, F.G. \& FORNASIERI FILHO, D. Sucessão de cultivo de feijãoarroz com doses de adubação nitrogenada após adubação verde, em semeadura direta. Bragantia, 62:417-428, 2003.

BRITO, M.M.P.; MURAOKA, T. \& SILVA, E.C. Contribuição da fixação biológica de nitrogênio, fertilizante nitrogenado e nitrogênio do solo no desenvolvimento de feijão e caupi. Bragantia, 70:206-215, 2011.

CARVAlHO, M.A.C.; ARF, O.; SÁ, M.E.; BUZETTI, S.; SANTOS, N.C.B. \& BASSAN, D.A.Z. Produtividade e qualidade de sementes de feijoeiro (Phaseolus vulgaris L.) sob influência de parcelamentos e fontes de nitrogênio. R. Bras. Ci. Solo, 25:617-624, 2001.

CERETTA, C.A. Adubação nitrogenada no sistema plantio direto: Sucessão aveia/milho. In: CONFERÊNCIA ANUAL DE PLANTIO DIRETO, 3., Ijuí, 1998. Anais... Passo Fundo, Aldeia Norte, 1998. p.49-62.

COSTA, R.C.L.; LOPES, N.F.; OLIVA, M.A. \& BARROS, N.F. Efeito da água e do nitrogênio sobre a fotossíntese, respiração e resistência estomática em Phaseolus vulgaris. Pesq. Agropec. Bras., 23:1371-1379, 1988.

CRUSCIOL, C.A.C. \& SORATTO, R.P. Sistemas de produção e eficiência agronômica de fertilizantes. In: PROCHNOW, L.I.; CASARIN, V. \& STIPP, S.R., orgs. Boas práticas para uso eficiente de fertilizantes. Piracicaba, IPNI, 2010. v.1. p.229-275.

EMPRESA BRASILEIRA DE PESQUISA AGROPECUÁRIA EMBRAPA. Sistema brasileiro de pesquisa do solo. Sistema brasileiro de classificação de solos. 2.ed. Rio de Janeiro, Embrapa Solos, 2006. 306p.

FARINELLI, R.; LEMOS, L.B.; PENARIOL, F.G.; EGÉA, M.M. \& GASPAROTO, M.G. Adubação nitrogenada de cobertura no feijoeiro, em plantio direto e convencional. Pesq. Agropec. Bras., 41:307-312, 2006.

FERNANDES, F.C.S.; LIBARDI, P.L. \& CARVALHO, L.A. Internal drainage and nitrate leaching in a corn-black oat-corn succession with two split nitrogen applications. Sci. Agric., 63:483-492, 2006.

FERNÁNDEZ, F.; GEPTS, P. \& LOPES, M. Etapas de desarrollo de la planta de frijol (Phaseolus vulgaris L.). Cali, Centro Internacional de Agricultura Tropical, 1986. 34p.

FIGUEIREDO, C.C.; RESCK, D.V.S.; GOMES, A.C.; FERREIRA, E.A.B. \& RAMOS, M.L.G. Carbono e nitrogênio da biomassa microbiana em resposta a diferentes sistemas de manejo em um Latossolo Vermelho no Cerrado. R. Bras. Ci. Solo, 31:551-562, 2007.

HERNANI, L.C.; KURIHARA, C.H. \& SILVA, W.M. Sistema de manejo do solo e perdas de nutriente e matéria orgânica por erosão. R. Bras. Ci. Solo, 23:145-154, 1999.

INFORZATO, R. \& MIYASAKA, S. Sistema radicular do feijoeiro em dois tipos de solo do Estado de São Paulo. Bragantia, 22:477-481, 1963.

KLUTHCOUSKI, J.; AIDAR, H.; THUNG, M.; OLIVEIRA, F.R.A. \& COBUCCI, T. Manejo antecipado do nitrogênio nas principais culturas anuais. Santo Antônio de Goiás, Embrapa Arroz e Feijão, 2005. 63p. (Documentos Embrapa Arroz e Feijão, 188)
LANGE, A.; LARA CABEZAS, W.A.R. \& TRIVELIN, P.C.O. Recuperação do nitrogênio das fontes sulfato e nitrato de amônio pelo milho em sistema semeadura direta. Pesq. Agropec. Bras., 43:123-130, 2008.

LOVATO, T.; MIELNICZUK, J.; BAYER, C. \& VEZZANI, F. Adição de carbono e nitrogênio e sua relação com os estoques no solo e com o rendimento do milho em sistemas de manejo. R. Bras. Ci. Solo, 28:175-187, 2004.

MAI, M.E.M.; CERETTA, C.A.; BASSO, C.J.; SILVEIRA, M.J.; PAVINATO, A. \& PAVINATO, P.S. Manejo da adubação nitrogenada na sucessão aveia-preta/milho no sistema plantio direto. Pesq. Agropec. Bras., 38:125-131, 2003.

MAIA, S.C.M.; SORATTO, R.P.; NASTARO, B. \& FREITAS, L.B. The nitrogen sufficiency index underlying estimates of nitrogen fertilization requirements of common bean. R. Bras. Ci. Solo, 36:183-192, 2012.

MALAVOLTA, E.; VITTI, G.C. \& OLIVEIRA, S.A. Avaliação do estado nutricional de plantas: Princípios e aplicações. Piracicaba, Potafos, 1997. 308p.

MARSCHNER, H. Mineral nutrition of higher plants. 2.ed. London, Academic Press, 1995. 889p.

OLIVEIRA, I.P.; ARAUJO, R.S. \& DUTRA, L.G. Nutrição mineral e fixação biológica de nitrogênio. In: ARAUJO, R.S.; RAVA, C.A.; STONE, L.F. \& ZIMMERMANN, M.J.O., coords. Cultura do feijoeiro comum no Brasil. Piracicaba, Potafos, 1996. p.169-221.

RAIJ, B.van; ANDRADE, J.C.; CANTARELLA, H. \& QUAGGIO, J.A. Análise química para avaliação da fertilidade de solos tropicais. Campinas, Instituto Agronômico de Campinas, 2001. 284p.

RAIJ, B.van. Fertilidade do solo e adubação. Piracicaba, Ceres/ Potafos, 1991. 343p.

RHEINHEIMER, D.S.; KAMINSKI, J.; LUPATINI, G.C. \& SANTOS, E.J.S. Modificações em atributos químicos de solo arenoso sob sistema de plantio direto. R. Bras. Ci. Solo, 22:713-721, 1998.

RIGHI, C.A. \& BERNARDES, M.S. Disponibilidade de energia radiante em um sistema agroflorestal com seringueiras: produtividade do feijoeiro. Bragantia, 67:533-540, 2008.

SÁ, J.C.M. Manejo da fertilidade do solo no sistema plantio direto. In: SIQUEIRA, J.O.; MOREIRA, F.M.S; LOPES, A.S.; GUILHERME, L.R.G.; FAQUIN, V.; FURTINI NETO, A.E. \& CARVALHO J.G. (Ed.). Interrelação fertilidade, biologia do solo e nutrição de plantas. Lavras, SBCS/UFLA, 1999. p. 291-309.

SÁ, J.C.M. Manejo do nitrogênio na cultura do milho no sistema plantio direto. Passo Fundo, Aldeia Norte, 1996. 24p.

SANTOS, A.B. \& FAGERIA, N.K. Manejo do nitrogênio para eficiência de uso por cultivares de feijoeiro em várzea tropical. Pesq. Agropec. Bras., 42:1237-1248, 2007.

SORATTO, R.P. Formas de antecipação e fontes de nitrogênio para feijoeiro em sucessão à gramíneas forrageiras no sistema plantio direto. Botucatu, Universidade Estadual Paulista, 2011. 131p. (Tese de Livre-Docência) 
SORATTO, R.P.; CARVALHO, M.A.C. \& ARF, O. Nitrogênio em cobertura no feijoeiro cultivado em plantio direto. R. Bras. Ci. Solo, 30:259-265, 2006.

SORATTO, R.P.; CARVALHO, R.L.T.; PILON, C.; GIORGETTI, A.A. \& SOUZA, G.D. Épocas de antecipação do nitrogênio para o feijoeiro no sistema plantio direto após milho solteiro ou consorciado com Brachiaria brizantha. In: FERTBIO 2008. Londrina, 2008. Resumos... Londrina, Sociedade Brasileira de Ciência do Solo, 2008. CD-ROM

SORATTO, R.P.; FERNANDES, A.M.; SOUZA, E.F.C. \& SOUZA-SCHLICK, G.D. Produtividade e qualidade dos grãos de feijão em função da aplicação de nitrogênio em cobertura e via foliar. R. Bras. Ci. Solo, 35:2019-2028, 2011.

SORATTO, R.P.; SILVA, T.R.B.; ARF, O. \& CARVALHO, M.A.C. Níveis e épocas de aplicação de nitrogênio em cobertura no feijoeiro irrigado em plantio direto. Cult. Agron., 10:89-99, 2001.
SOUZA, E.F.C.; SORATTO, R.P. \& PAGANI, F.A. Aplicação de nitrogênio e inoculação com rizóbio em feijoeiro cultivado após milho consorciado com braquiária. Pesq. Agropec. Bras., 46:370-377, 2011.

TEIXEIRA, C.M.; CARVALHO, G.J.; ANDRADE, M.J.B.; FURTINI NETO, A.E. \& MARQUES, E.L.S. Palhadas e doses de nitrogênio no plantio direto do feijoeiro. Acta Sci. Agron., 27:499-505, 2005.

VIEIRA, N.M.B.; ANDRADE, M.J.B.; CARVALHO, L.P. \& REZENDE, P.M. Accumulation of macronutrients by different common bean cultivars grown in different plant densities in no-tillage crop system. Ann. Rep. Bean. Improv. Coop., 52:132-133, 2009.

WUTKE, E.B.; BULISANI, E.A. \& MASCARENHAS, H.A.A. Curso de adubação verde no Instituto Agronômico, 1. Campinas, Instituto Agronômico de Campinas, 1993. 89p. 